\section{Vietnam Journal of Agricultural Sciences}

\title{
The First Record of Adult Spotted Sea Bass (Lateolabrax maculatus, McClelland, 1844) from the Coastal Waters of Quang Ninh Province, Vietnam
}

\section{Nguyen Van Giang ${ }^{1}$, Phan Thanh $\mathrm{Nghi}^{2}$ \& Nguyen Bich Hanh ${ }^{3}$}

${ }^{1}$ Research Institute for Marine Fisheries, Haiphong 182180, Vietnam

${ }^{2}$ Bai Tu Long National Park, Quang Ninh 205350, Vietnam

${ }^{3}$ Quang Ninh Department of Science and Technology, Quang Ninh 200000, Vietnam

\begin{abstract}
Spotted sea bass (Lateolabrax maculatus, McClelland, 1844) is a species belonging to the genus Lateolabrax (Lateolabracidae), and is characterized by the many distinct black spots on the bodies of mature fish. For the first time, six specimens have been recorded in Quang Ninh province. The specimens were collected from Luon Cave in Bai Tu Long National Park in May-June 2019. The new specimens collected from Quang Ninh, Vietnam are different from the recorded specimens from Japan, Korea, Taiwan, and China in terms of lateral line scales (LLS) as the samples collected in Quang Ninh, Vietnam have 94-97 scales and the samples collected from the other countries have 66-82 scales. Phylogenetic analysis of the $16 \mathrm{~S}$ rDNA sequence confirmed that all of the samples collected in Quang Ninh, Vietnam belonged to the species of spotted sea bass.
\end{abstract}

\section{Keywords}

Bai Tu Long, Lateolabracidae, morphology, national park, phylogenetic

\section{Introduction}

The family Lateolabbracidae, order Perciformes, is comprised of eight species and three genera worldwide, including the genus Lateolabrax, which consists of three species: sea bass (SB), Lateolabrax japonicus (Cuvier, 1828); spotted sea bass (SSB), Lateolabrax maculatus (McClelland, 1844); and blackfin sea bass, Lateolabrax latus (Katayama, 1957) (Bae et al., 2016). The sea basses of the genus Lateolabrax are common East Asian coastal marine fishes (occasionally also occurring in freshwater) (Yokogawa, 2019). Species of the Lateolabrax complex (including L. japonicus and L. maculatus) are morphologically similar, which 
has led to considerable confusion regarding their taxonomic status. Generally, L. maculatus (widely considered to be a color variant of $L$. japonicus) is characterized by many clear black dots on the dorsolateral body, whereas on $L$. japonicus, the black dots are absent or faded in adult fish (Katayama, 1984; Kang, 2000). Thus, SSB and SB are generally distinguished by the presence or absence, respectively, of black spots. However, because some individuals of $L$. japonicus have black spots on the dorsolateral body, even in the adult stages, distinguishing between the two species solely based on the presence of black spots is difficult (Bae et al., 2016).

In terms of external morphology and anatomical structure, many previous publications have pointed out the different characteristics of species in the Lateolabrax genus, including Chyung (1977), Yokogawa \& Seki (1995), Park et al. (1996), Kim \& Jun (1997), Yokogawa et al. (1997), Kang (2000), and Yokogawa (2019). In addition to morphology studies, DNA molecular genetics studies have also been conducted by Park et al. (1996), Han et al. (2015), and Bae et al. (2016), indicating differences among species in the genus Lateolabrax.

In Vietnam, Lateolabrax fish have been identified as L. japonicus by Nguyen Nhat Thi (1991), Kottelat (2001), Nguyen Nhat Thi \& Nguyen Van Hao (2005), and Nguyen Huu Duc et al. (2014). Recently, L. maculatus also has been identified in the estuary area of northern Vietnam. However, in addition to this new insight into the distribution of Lateolabrax maculatus, the authors also said that SSB is distributed along coasts from the Yellow to East Seas (South China Seas) (Katayama, 1984; Yamada et al., 2007; Yokogawa, 2013), of which the northern Vietnamese coasts facing the Gulf of Tonkin are probably the most southern distribution for the genus Lateolabrax (Nguyen Nhat Thi, 1991; Kottelat, 2001; Nguyen Nhat Thi \& Nguyen Van Hao, 2005; Tran et al., 2017; Nguyen et al., 2019).

During our recent field trip in the Bai Tu Long National Park of Quang Ninh Province in northern Vietnam, we collected six specimens of spotted sea bass which agreed with the previously published descriptions of $L$. maculatus. They could be assigned to $L$. maculatus based on morphological characters and molecular data, and we reported spotted sea bass adults from Vietnam for the first time. Hence, this study aimed to examine the morphological characteristics of L. maculatus in adulthood and its distribution pattern in relation to the cave environment, which are fundamental to understanding the essential habitat and conservation needs of the species.

\section{Materials and Methods}

Field surveys were conducted in May and June 2019 in Bai Tu Long National Park, Quang Ninh Province along the northern coast of Vietnam (Figure 1). We used handline fishing to collect the fish samples living in the cave, including fishing rods, single hooks, and live shrimp bait. Samples of muscle tissue were preserved separately in $95 \%$ ethanol, and voucher specimens were fixed in approximately $80 \%$ ethanol and later transferred to $70 \%$ ethanol for permanent storage. The specimens were deposited at the Research Institute for Marine Fisheries (RIMF), Hai Phong, Vietnam.

Morphological characters. Dimensions of the fish were taken with digital calipers to the nearest $0.1 \mathrm{~mm}$, and the methods of measurements and counts followed Yokogawa (2019). The following abbreviations were used for the measurable characteristics: AFL, anal fin (longest ray) length; BD, body depth; BWT, body width; CFL, caudal fin length; CFND, caudal fin notch depth; CPAD, caudal peduncle anterior depth; CPD, caudal peduncle depth; CPL, caudal peduncle length; FDFL, first dorsal fin (longest spine) length; HL, head length; IOW, inter-orbital width; LJL, lower jaw length; OD, orbital diameter; PAL, pre-anus length; PDL, pre-dorsal length; POL, post-orbital width; POPW, post-orbital preopercular width; P1FL, pectoral fin length; P2FL, pelvic fin length; SDFL, second dorsal fin (longest ray) length; SL, standard length; SNL, snout length; SOW, sub-orbital width; and UJL, upper jaw length. The following abbreviations were used for the counting characteristics: AFR, anal-fin ray; AFS, anal fin spine-ray; DFR, dorsal-fin 
soft ray; DFS, dorsal-fin spine; LGR, lower-limb gill raker; LLS, pored scale on lateral line; P1FR, pectoral fin ray; P2FS, pelvic fin spineray; P2FR, penvic-fin ray; SAL, scale above lateral line; SBL, scale below lateral line; TGR, total gill raker; and URG, upper-limb gill raker.

Molecular data and phylogenetic analyses. In order to support the generic placement of the species, we obtained muscle samples from the species. Total DNA was extracted from $30 \mathrm{mg}$ of fish muscle tissue using tissue extraction kits from Wizard ${ }^{\circledR}$ Genomic DNA Purification (Promega, USA) following the manufacturer's instructions. The study conducted PCA to amplify the 16S rDNA gene fragment using the primer pair 16Sar 5'CGCCTGTTTATCAAAAACAT-3' and 16Sbr

\section{5'-CCGGTCTGAACTCAGATCACGT-3'}

(Palumbi, 1996). The PCR reaction was conducted with a total volume of $50 \mu \mathrm{L}$, including $5 \mu \mathrm{L}$ DNA, $10 \mu \mathrm{L}$ Green Gotaq ${ }^{\circledR}$ Flexi Buffer 5X, $3 \mu \mathrm{L} \mathrm{MgCl} 225 \mathrm{mM}, 2 \mu \mathrm{L}$ dNTPs, 2 $\mu \mathrm{L}$ of each primer $(10 \mathrm{mM}), 0.25 \mu \mathrm{L}$ Taq polymerase ( 5 unit $\mu \mathrm{L}^{-1}$ ), and enough water to fill the volume. The reactions were run on iCycler thermal cyclers (Bio-Rad) according to the temperature cycle: initial denaturation at $94^{\circ} \mathrm{C}$ for 3 minutes, then 38 cycles of $94^{\circ} \mathrm{C}$ for 30 seconds, $48^{\circ} \mathrm{C}$ for 45 seconds, and $72^{\circ} \mathrm{C}$ for 30 seconds, and the final extension step at $72^{\circ} \mathrm{C}$ for 5 minutes. The PCR products were electrophoresis tested for results on $1.5 \%$ agarose gel containing ethidium bromide for DNA staining.

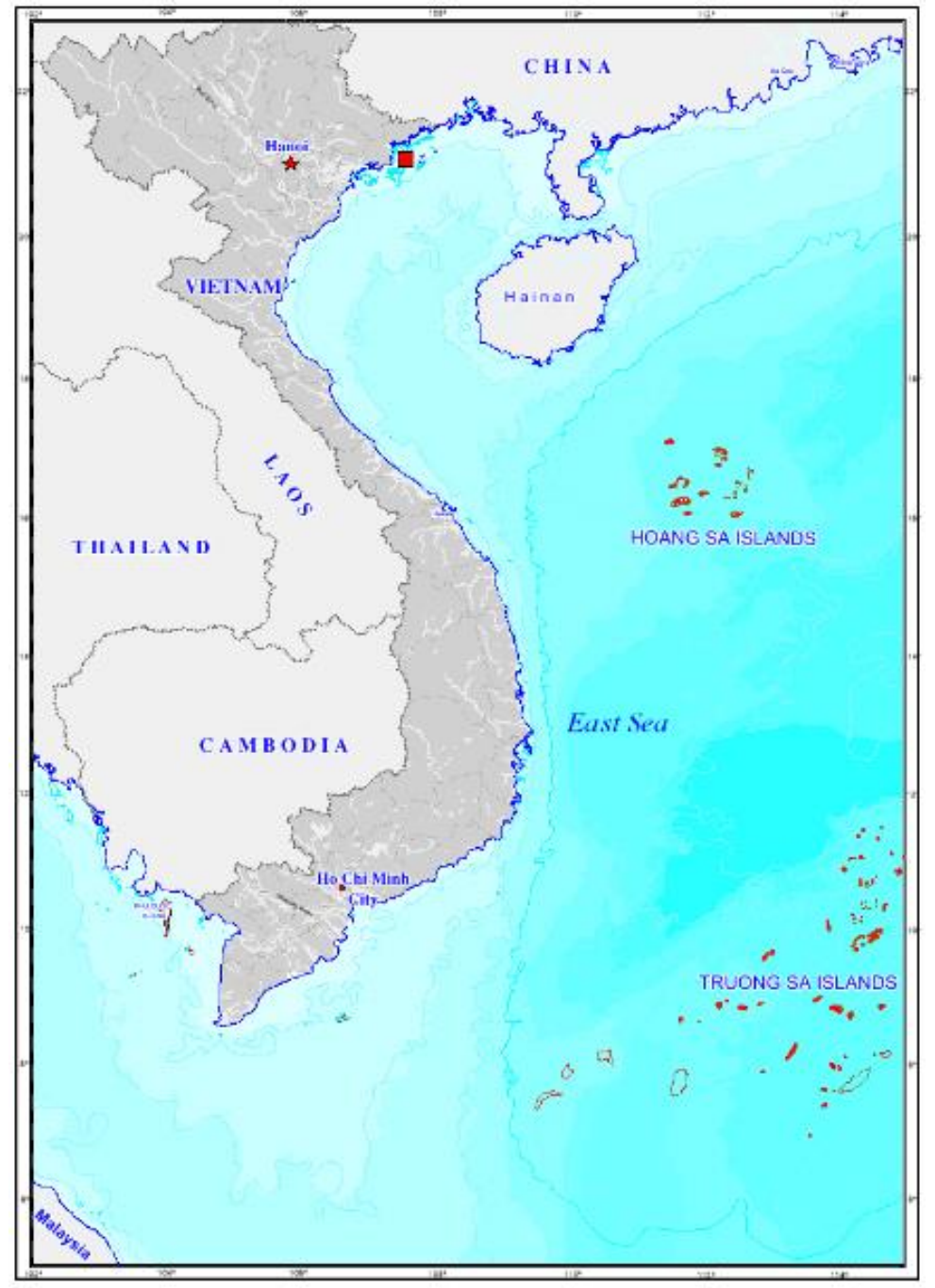

Figure 1. Map showing the survey site (red square) in Bai Tu Long National Park, Quang Ninh Province, northern coast of Vietnam 
The PCR products were purified by Promega's Wizard Gel and PCR Clean-up System kits according to the manufacturer's instructions and used as direct templates for the pre-sequential reactions according to the dyelabeled dideoxy terminator principle (Big Dye Terminator v.3.1, Applied Biosystems) with similar primers to those used in the PCR reaction under the following thermal cycler program: $96^{\circ} \mathrm{C}$ for 20 seconds, $50^{\circ} \mathrm{C}$ for 20 seconds, and finally $60^{\circ} \mathrm{C}$ for 4 minutes. The products were then analyzed using an ABI Prism 3.700 DNA Analyzer (Applied Biosystems).

The sequences were connected using Geneious Pro 5.5.7 software (Kearse et al., 2012) and verified by the Nucleotide BLAST program on Gen Bank's website (ncbi.nlm.nih.gov/Blast.cgi). The sequences were aligned with BioEdit v.7.0.1 (Hall, 1999) using the Clustax feature, in order to conduct checks and truncate a number of positions to achieve a common length for all the sequences. Analysis of the phylogenetic relationships was conducted based on the maximum likelihood algorithm using MEGA 6 software (Tamura et al., 2013) with the repeatability of 1000 times. The bootstrap (BT) value was calculated to determine the accuracy of the algorithm.

\section{Results}

\section{Description of the specimen from Vietnam}

\section{Specimens examined}

Six specimens, RIMF0001 (SL 419.9mm), RIMF0002 (SL 363.3mm), RIMF0003 (SL 362.2mm), RIMF004 (SL 358.8mm), RIMF0005 (SL 543.3mm), and RIMF006 (SL 542.2mm), were collected by Phan Thanh Nghi, Tran Hoai Nam, and Nguyen Van Giang in May and June 2019, within Cave Luon-Ang Cai De in Bai Tu Long National Part (215'27" N 107³3'42" E), Van Don district, Quang Ninh province. The morphological characters of the Vietnam specimens agreed well with the previously reported description of Lateolabrax maculatus.

\section{Description}

The general appearance of the specimens is shown in Figure 2, and the meristic and morphometric data of the six specimens are given in Table 1. The head was slightly longer and pointed [31.2 (30.4-32.5) \% of SL], while the dorsal and ventral profiles were straight. The snout was shorter than a head length behind the eye, and longer than the eye diameter [21.7 (21.123) $\%$ of HL]. The eyes were near the dorsal region of the head, and shorter than the interorbital width [15.1 (14.2-16) \% of HL]. The inter-orbital area was slightly convex. The mouth had a lower jaw longer than the upper jaw, and was without barbels.

The body height was compressed [24 (22.625.7) \% of SL], about 1.8-2.0 times the body width, and the caudal peduncle was slender, about 2.0-2.5 times longer than deep [20.1 (18.4-22.1) $\%$ of SL]. The highest body point was at the origin of the dorsal fin, and the lowest at the caudal peduncle. The dorsal body profile was convex, while the ventral profile was straight or slightly rounded. The lateral line was complete with 94-97 scales, and there were 14-16 scales above the lateral line and 16-17 scales below the lateral line.

There were two dorsal fins, positioned high, interconnected with 12-13 spines and with 12-14 soft rays [13.8 (12.6-14.4) \% of SL)]. The first spine was the lowest and highest was the $5^{\text {th }}$ ray. The dorsal-fin origin was inserted slightly in front of vertical with the pelvic-fin origin. The distas edge of first dorsal fin was concave and the second dorsal fin was convex. The pectoral fin was rounded with one simple and 15 branched rays. The pelvic fin was rounded, with one spine ray and 5 branched rays, and the fin origin scale was present. The anus was immediately in front of the anal fin. The anal fin had three spine rays and was short [14.2 (12.1-15.6) \% of SL). The caudal fin was deeply forked with $9+8$ being branched.

\section{Color in life}

The head was colored dark turquoise on the back, dark gray around the orbital and on the side, dark gray on the upper jaw, lower jaw, and maxilla, and silver on the posterior maxilla and preopercle. The body was dark brown on the back with many clear black spots on and above 
The first record of adult spotted sea bass from the coastal waters of Quang Ninh province, Vietnam

Table 1. Morphometric and meristic characters of L. maculatus, mean, and range

\begin{tabular}{|c|c|c|c|c|}
\hline Character & Abbreviation & $\mathrm{N}$ & Mean \pm SD & Range \\
\hline Standard length $(\mathrm{mm})$ & SL & 6 & $431.6 \pm 89$ & $358.8-543.3$ \\
\hline \multicolumn{5}{|l|}{ Morphometrics (\% SL) } \\
\hline Pre-anus length & PAL & 6 & $65 \pm 1.7$ & $63.5-67.2$ \\
\hline Body depth & $\mathrm{BD}$ & 6 & $24 \pm 1.1$ & $22.6-25.7$ \\
\hline Body width & BWT & 6 & $12.8 \pm 0.7$ & $11.9-13.7$ \\
\hline Caudal peduncle depth & CPD & 6 & $9.2 \pm 0.6$ & $8.4-9.9$ \\
\hline Caudal peduncle anterior depth & CPAD & 6 & $10 \pm 4.9$ & $11.3-13$ \\
\hline Caudal peduncle length & CPL & 6 & $20.1 \pm 1.2$ & $18.4-22.1$ \\
\hline Pre-dorsal length & PDL & 6 & $33.3 \pm 0.9$ & $32.3-34.4$ \\
\hline First dorsal fin (longest spine) length & FDFL & 6 & $13.8 \pm 0.7$ & $12.6-14.4$ \\
\hline Second dorsal fin (longest ray) length & SDFL & 6 & $12.5 \pm 1.1$ & $11.2-14.1$ \\
\hline Caudal fin length & CFL & 6 & $19.9 \pm 1.7$ & $18.2-22.6$ \\
\hline Caudal fin notch depth & CFND & 6 & $6.4 \pm 1$ & $4.9-7.4$ \\
\hline Anal fin (longest ray) length & AFL & 6 & $14.2 \pm 1.4$ & $12.1-15.6$ \\
\hline Pectoral fin length & P1FL & 6 & $16.6 \pm 1.5$ & $15.1-18.7$ \\
\hline Pelvic fin length & P2FL & 6 & $17.1 \pm 1.3$ & $15.1-19.3$ \\
\hline Head length & $\mathrm{HL}$ & 6 & $31.2 \pm 0.8$ & $30.4-32.5$ \\
\hline Snout length & SNL & 6 & $6.8 \pm 0.2$ & $6.6-7$ \\
\hline Post-orbital preopercular width & POPW & 6 & $7.2 \pm 0.4$ & $6.8-7.7$ \\
\hline \multicolumn{5}{|l|}{$\% \mathrm{HL}$} \\
\hline Snout length & SNL & 6 & $21.7 \pm 0.7$ & $21.1-23$ \\
\hline Orbital diameter & OD & 6 & $15.1 \pm 0.8$ & $14.2-16$ \\
\hline Inter-orbital width & IOW & 6 & $18.7 \pm 0.9$ & $17.4-20$ \\
\hline Sub-orbital width & sow & 6 & $13.3 \pm 0.7$ & $12.7-14.5$ \\
\hline Post-orbital width & POL & 6 & $63.4 \pm 1.3$ & $61.7-65$ \\
\hline Post-orbital preopercular width & POPW & 6 & $23.2 \pm 0.9$ & $21.4-24$ \\
\hline Upper jaw length & UJL & 6 & $44.2 \pm 1.4$ & $42.6-46$ \\
\hline Lower jaw length & LJL & 6 & $49 \pm 1.7$ & $46.6-51.1$ \\
\hline \multicolumn{5}{|l|}{ Counts } \\
\hline Dorsal fin spine and soft ray & DFS, DFR & 6 & XII-XIII, 12-14 & XII-XIII, 12-14 \\
\hline Anal fin spine-ray and fin ray & AFS, AFR & 6 & III, 8 & III, 8 \\
\hline Pectoral fin ray & P1FR & 6 & $15 \pm 0$ & 15 \\
\hline Pelvic fin spine-ray & P2FS, P2FR & 6 & I, 5 & I, 5 \\
\hline Pored scale on lateral line & LLS & 6 & $95.3 \pm 1.2$ & $94-97$ \\
\hline Scale above lateral line & SAL & 6 & $15 \pm 0.9$ & $14-16$ \\
\hline Scale below lateral line & SBL & 6 & $16.8 \pm 0.4$ & $16-17$ \\
\hline Upper-limb gill raker & UGR & 6 & $8 \pm 0$ & 8 \\
\hline Lower-limb gill raker & LGR & 6 & $16.2 \pm 0.4$ & $16-17$ \\
\hline Total gill raker & TGR & 6 & $24.2 \pm 0.4$ & $24-25$ \\
\hline
\end{tabular}




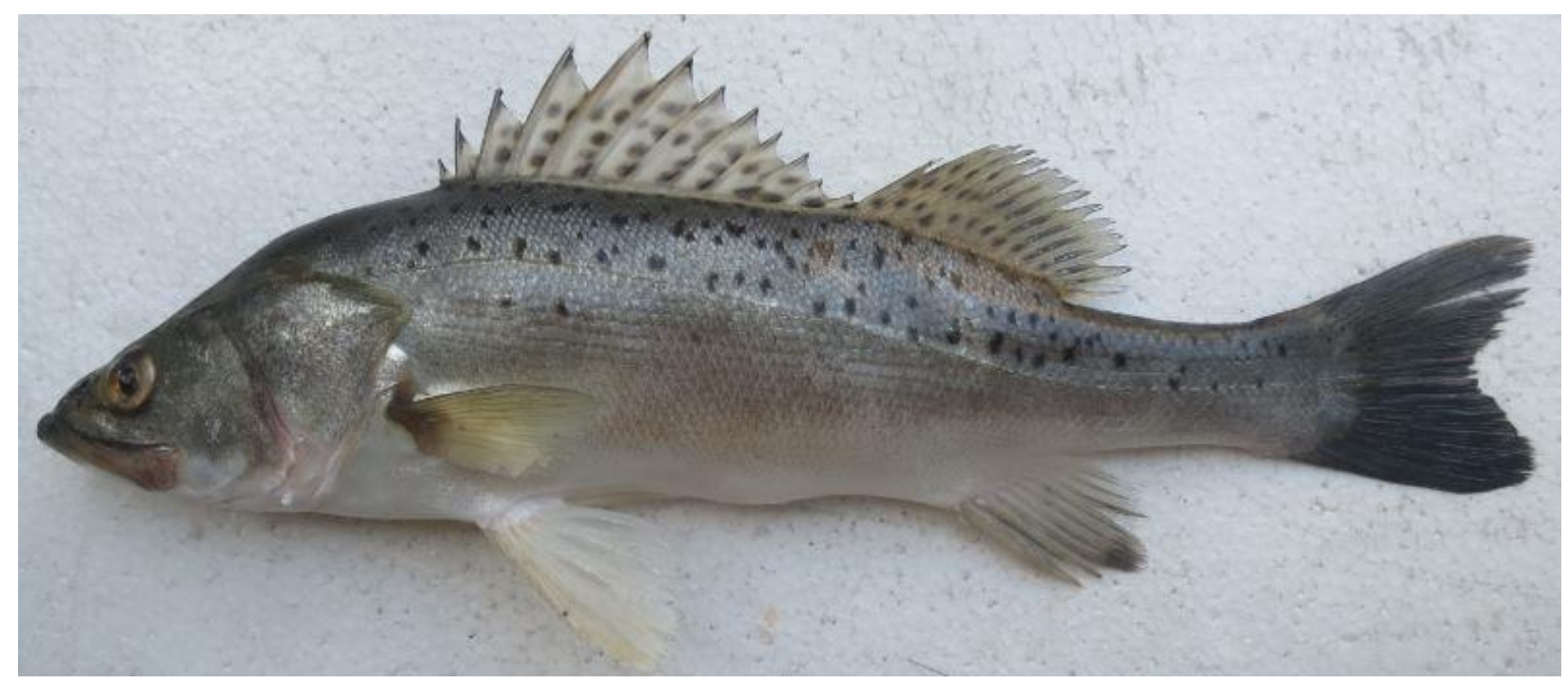

Figure 2. Lateral view of Lateolabrax maculatus specimen (RIMF0002, $363.3 \mathrm{~mm} \mathrm{SL)}$

the lateral line and a few spots below. The side of the body was light turquoise and silver white on the ventral surface. The dorsal fin was dark turquoise at the origin and bold on the rays. In between the rays, there were black dots on the interradial membranes. The pectoral and pelvic fins were yellowish green in the first rays or covered the whole fins. The anal fin was plain greyish while the caudal fin was dark gray.

\section{Ecological notes}

All six specimens of $L$. maculatus were found in the Luon Cave of Bai Tu Long National Park, Quang Ninh Province, Vietnam (Figure 3). Spotted sea bass live in caves, surrounded by layered limestone, at a depth range of $2.2-2.5 \mathrm{~m}$. The water conditions were $25.5-27.9^{\circ} \mathrm{C}, \mathrm{pH} 6.82-$ 8.06 , DO $4.72-5.43 \mathrm{mg} \mathrm{L} \mathrm{L}^{-1}$, and salinity 5$30.5 \%$.

\section{Phylogenetic analysis}

Studying the genetic relationships of the three species in the Lateolabrax genus was based on $16 \mathrm{~S}$ rDNA fragments. Data used for the genetic analysis were retrieved from Gen Bank with the three accession codes KT852999.1, KR780682.1, and KR780681.1, and our two gene sequences labeled RIMF0001 and RIMF0002. The phylogenetic tree, as seen in Figure 4, shows a clear grouping of genes of the same species into a branch with a high bootstrap value (99\%), which is distinguished from species in different branches. This confirmed that the recently collected specimens from Bai Tu Long National Park, Quang Ninh, Vietnam belong to Lateolabrax maculatus and differ from the two species L. japonicus and L. latus.

\section{Discussion}

Only minor morphological differences were identified between the populations collected in Vietnam's Quang Ninh waters and those previously described and disclosed in the waters of Japan, Korea, Taiwan, and China (e.g., the pored scale on the lateral line - in the present study 94-97 LLS vs. 66-82 LLS of L. maculatus). In particular, as only six individuals of this species are known, we consider the new findings from Vietnam as conspecific with Lateolabrax maculatus, which is supported by strong genetic compliance.

Numerous studies on morphological characteristics have pointed out the differences between species in the genus Lateolabrax. Yokogawa (2019) pointed out that Lateolabrax maculatus is easily distinguished from other seabass species. It differs from $L$. latus by 


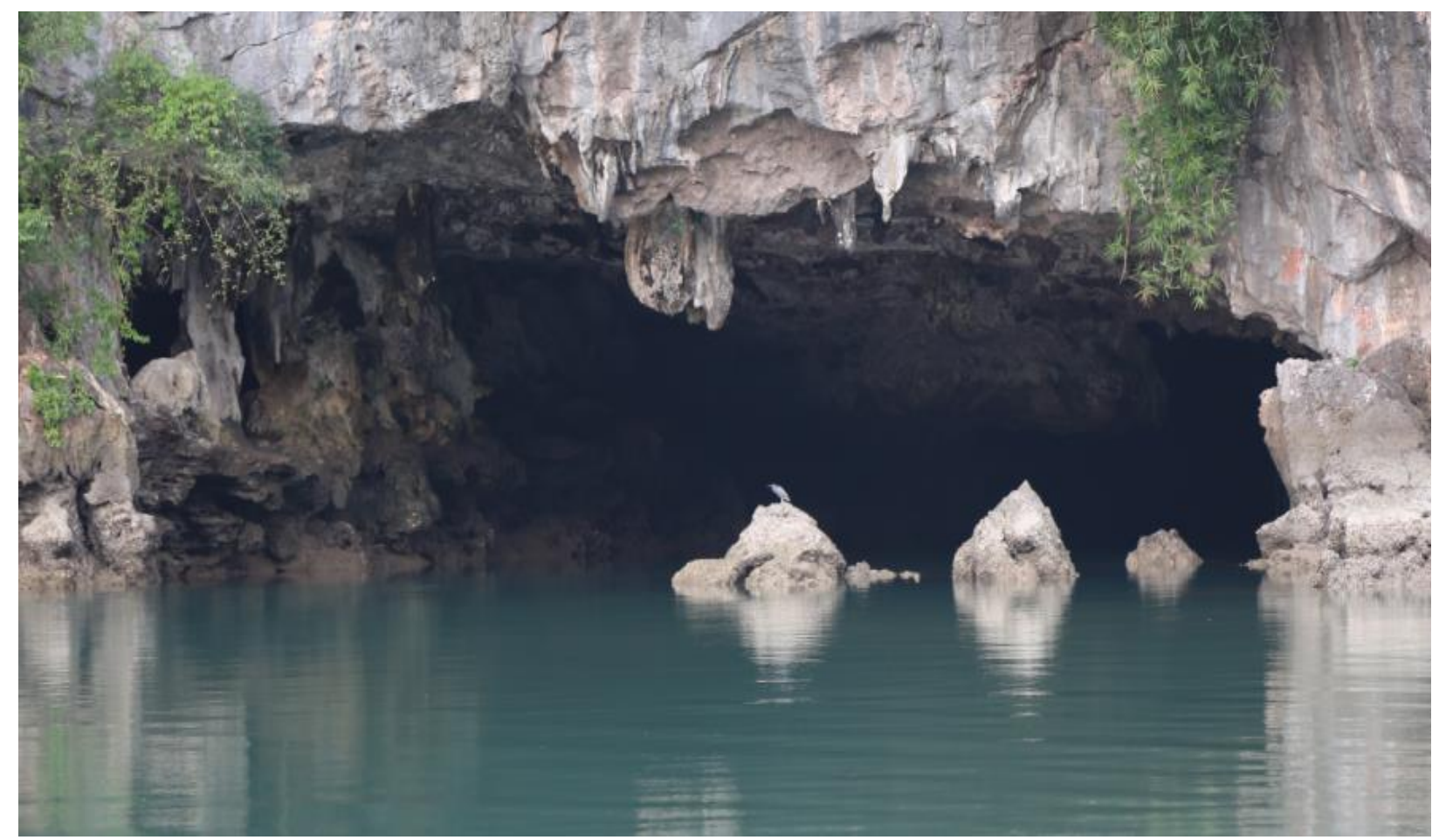

Figure 3. Habitat of Lateolabrax maculatus, in Luon Cave of Bai Tu Long National Park, Quang Ninh Province, Vietnam

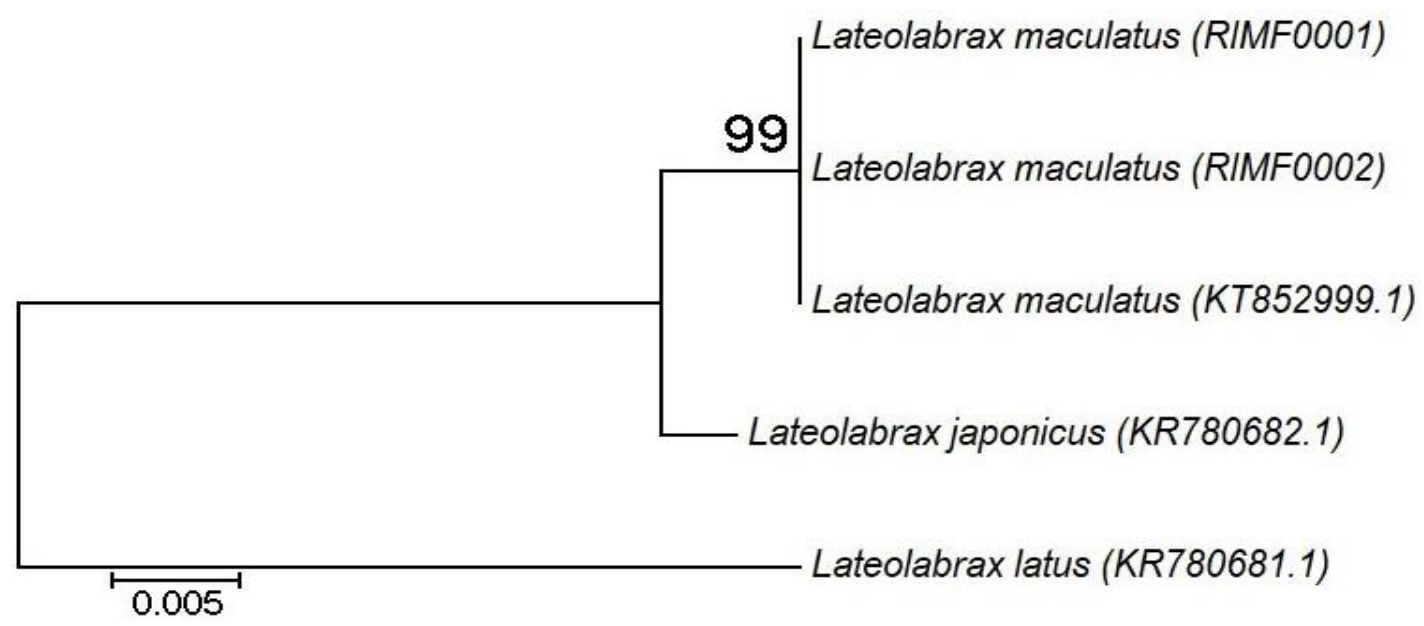

Figure 4. Maximum likelihood tree of Lateolabrax based on mitochondrial $16 S$ rRNA sequence data (603 aligned sites). The number above the branches is the bootstrap value (> 95\%).

having a caudal peduncle anterior depth [\% of standard length (SL) $] \leq 15 \%$ (vs. $>15 \%$ ), snout length ( $\%$ of SL) $\leq 9 \%$ (vs. > $\% \%$ ), upper and lower jaw lengths [\% of head length (HL) $\leq$ $45 \%$ and $49 \%$ (vs. $>45 \%$ and $49 \%$, respectively), 14 or fewer dorsal fin rays (vs. 15 or 16, rarely 14 ), and anal fin ray counts of eight or fewer (vs. 9-11 anal fin rays). Lateolabrax maculatus differs from $L$. japonicus by the following features: a post-orbital preopercular width
(POPW) $[\%$ of snout length (SNL) $] \geq 90 \%$ (vs. $<$ $90 \%)$ [POPW $(\%$ of $\mathrm{SL}) \geq 7.5 \%$ in specimens $\leq$ $200 \mathrm{~mm} \mathrm{SL}$ (vs. $<7.5 \%$ ), SNL ( $\%$ of SL) $\leq 7.7 \%$ in specimens $>200 \mathrm{~mm} \mathrm{SL}$ (vs. $\geq 7.7 \%$ )], 18 or 19 caudal vertebrae (usually) [rarely $20(9.2 \%)$ ] (vs. 20 caudal vertebrae (usually) or 21) [rarely $19(13.5 \%)]$ ), 34 or 35 total vertebrae (usually) [rarely $36(6.6 \%)$ ] (vs. 36 total vertebrae (usually) or 37 [rarely 35 (13.5\%)]), straight first anal pterygiophore (vs. modestly arched first 
anal pterygiophore in specimens $\geq 90 \mathrm{~mm} \mathrm{SL}$ ), and usually many clear black spots on the lateral and dorsal body regions (usually on or partly below the lateral line) (vs. spots/dots absent on body in specimens $>260 \mathrm{~mm}$ SL (although some specimens $\leq 260 \mathrm{~mm}$ SL have some dots restricted to the upper part above the lateral line).

Chyung (1977) suggested that SSB could be distinguished from SB by body depth and the number of dorsal fin rays. Based on isozyme analysis, Park et al. (1996) revealed that SSB might be either a distinct species or subspecies. Kim and Jun (1997) indicated that SSB could be distinguished from SB by the number of gill rakers, body depth, and eye diameter. Furthermore, Kang (2000) reported that SSB was a distinct species (L. maculatus), different from L. japonicus in the number of vertebrae and gill rakers. On the other hand, Yokogawa et al. (1997) suggested that SB inhabiting the Ariake Sea in Japan might be SB-SSB hybrids, because the numbers of lateral line pores, gill rakers, and vertebrae were intermediate between those of SB (L. japonicus) and SSB or intermediate sea bass (ISB) (Lateolabrax sp.), and because SB and SSB (or ISB) share diverse haplotypes (Yokogawa \& Seki, 1995; Yokogawa et al., 1997).

Many studies have used nuclear DNA sequences to determine the differences among species in Lateolabrax such as the genetic divergence and genetic structure of the two closely related fish species $L$. maculatus and $L$. japonicus in the Northwestern Pacific were inferred from AFLP markers (Han et al., 2015); the genetic differences between wild and hatchery populations of Korean spotted sea bass (L. maculatus) were inferred from microsatellite markers (An et al., 2013); the population genetic structure of sea bass (L. japonicus) in Korea was based on multiplex PCR assays with 12 polymorphic microsatellite markers (An et al., 2014); the genetic divergence of fish in the genus Lateolabrax (Perciformes: Percichthyidae) (Yokogawa, 1998); and the complete mitochondrial genomes of three sea bass Lateolabrax (Perciformes, Lateolabracidae) species (Shan et al., 2016). All the genetic studies have shown them to be independent species.
The first discovery of a member of the genus Lateolabrax inside Vietnam once again confirms L. maculatus has been distributed in Vietnam's northern coast.

\section{Conclusions}

This was the first record of adult spotted sea bass (Lateolabrax maculatus, McClelland, 1844) from the coastal waters of Quang Ninh Province, Vietnam. The samples collected from Quang Ninh, Vietnam are different from the recorded specimens from Japan, Korea, Taiwan, and China in terms of lateral line scales as the samples collected in Quang Ninh, Vietnam have 94-97 scales and the samples collected from the other countries have 66-82 scales. Phylogenetic analysis of the $16 \mathrm{~S}$ rDNA sequence confirmed that all of the samples collected belonged to the species of spotted sea bass L. maculatus, a species of high economic value; but its growth, reproduction, nutrition, behavior, population, and habitat in the natural environment have not been studied. Therefore, the above issues are in need of continued research in order to conserve populations and breed breeding of the spotted sea bass L. maculatus in the future.

\section{Acknowledgments}

We are grateful to the directorate of Bai $\mathrm{Tu}$ Long National Park for support of our field research. The study was carried out with the support of the project entitled "Studying the value of the Tung and Ang ecosystems in the limestone and soil mountains alternating in Bai Tu Long National Park".

\section{References}

An H. S., Lee J. W., Kim H. Y., Kim J. B., Chang D. S., Park J. Y., Myeong J. I. \& An C. M. (2013). Genetic differences between wild and hatchery populations of Korean spotted sea bass (Lateolabrax maculatus) inferred from microsatellite markers. Genes and Genomics. 35(5): 671-680.

An H. S., Lee J. W., Kim H. Y., Kim J. B., Chang D. S., Park J. Y., Myeong J. I. \& An C. M. (2014). Population genetic structure of the sea bass (Lateolabrax japonicus) in Korea based on multiplex PCR assays with 12 polymorphic microsatellite markers. Genes 
and Genomics. 36(2): 247-259.

Bae S. E., Kim J.-K. \& Kim J. H. (2016). Evidence of incomplete lineage sorting or restricted secondary contact in Lateolabrax japonicus complex (Actinopterygii: Moronidae) based on morphological and molecular traits. Biochemical Systematics and Ecology. 66: 98-108.

Chyung M. (1977). The fishes of Korea. Seoul: Il Ji Sa Publ. Co.: 727 p.

Hall T. A. (1999). BioEdit: a user-friendly biological sequence alignment editor and analysis program for Windows 95/98/NT. Paper presented at the Nucleic acids symposium series.

Han Z., Han G., Wang Z., Shui B. \& Gao T. (2015). The genetic divergence and genetic structure of two closely related fish species Lateolabrax maculatus and Lateolabrax japonicus in the Northwestern Pacific inferred from AFLP markers. Genes and Genomics. 37(5): 471-477.

Kang C. (2000). Taxonomical studies on the Genus Lateolabrax (Pisces, Perciformes) from the Korean waters. Korea. M. SC. Thesis, University of Busan.

Katayama M. (1984). Lateolabrax japonicus (Cuvier). The fishes of the Japanese Archipelago. English text: 123.

Kearse M., Moir R., Wilson A., Stones-Havas S., Cheung M., Sturrock S., Buxton S., Cooper A., Markowitz S., Duran C., Thierer T., Ashton B., Meintjes P. \& Drummond A. (2012). Geneious Basic: an integrated and extendable desktop software platform for the organization and analysis of sequence data. Bioinformatics. 28(12): 1647-1649. DOI: 10.1093/bioinformatics/bts199.

Kim C. H. \& Jun J. C. (1997). Provisional classification of temperate sea bass, the genus Lateolabrax (Pisces: Moronidae) from Korea. Korean Journal of Ichthyology. 9(1): 108-113.

Kottelat M. (2001). Freshwater fishes of northern Vietnam: a preliminary check-list of the fishes known or expected to occur in northern Vietnam with comments on systematics and nomenclature. World Bank, Washington, DC (USA). East Asia and Pacific Region.

Nguyen Huu Duc, Pham Thi Hong Ninh \& Ngo Thi Mai Huong (2014). Fish species composition recorded in the Red River basin within the territory of the Thaibinh and Namdinh provinces, northern Vietnam. Biology Journal. 36(2) : 147-159. DOI: 10.15625/08667160/v36n2.5113 (in Vietnamese).

Nguyen Nhat Thi (1991). Marine Fishes of Vietnam Osteichthyes in the Gulf of Tonkin. Hanoi: Science and Technics Publishing House. (in Vietnamese)

Nguyen Nhat Thi \& Nguyen Van Hao (2005).
Lateolabracidae. In: Nguyen Van Hao (Ed.), Freshwater Fishes of Vietnam (Vol. III, pp. 162-164). Agriculture Publishing House: Hanoi (in Vietnamese).

Nguyen Thanh Nam, Tran Trung Thanh \& Tran Duc Hau (2019). New insights into early stages of Lateolabrax maculatus (McClelland, 1844) in a tropical estuary of northern Vietnam. Regional Studies in Marine Science. 30: 100727.

Palumbi S. R. (1996). Nucleic acids II: the polymerase chain reaction. Molecular Systematics. 205-247.

Park J.-Y., Kim K.-K. \& Kim Y. (1996). Genetic characterization of two types of sea bass, Lateolabrax japonicus in Korea by isozyme analysis. Journal of Aquaculture. 9(4): 437-444.

Shan B., Song N., Han Z., Wang J., Gao T. \& Yokogawa K. (2016). Complete mitochondrial genomes of three sea basses Lateolabrax (Perciformes, Lateolabracidae) species: genome description and phylogenetic considerations. Biochemical Systematics and Ecology. 67: 44-52.

Tamura K., Stecher G., Peterson D., Filipski A. \& Kumar S. (2013). MEGA6: molecular evolutionary genetics analysis version 6.0. Molecular Biology and Evolution. 30(12): 2725-2729.

Tran T. T., Tran H. D. \& Kinoshita I. (2017). Occurrence of two types of larvae of the Asian seaperch (Lateolabrax) in the estuaries of northern Vietnam. Ichthyological Research. 64(2): 244-249.

Yamada U., Tokimura M., Horikawa H. \& Nakabo T. (2007). Fishes and fisheries of the East China and Yellow Seas. Hadano: Tokai University.

Yokogawa K. (1998). Genetic divergence of fishes in genus Lateolabrax (Perciformes: Percichthyidae). Aquaculture Science. 46(3): 315-320.

Yokogawa K. (2013). Nomenclatural reassessment of the sea bass Lateolabrax maculatus (McClelland, 1844) (Percichthyidae) and a redescription of the species. Biogeography. 15: 21-32.

Yokogawa K. (2019). Morphological differences between species of the sea bass genus Lateolabrax (Teleostei, Perciformes), with particular emphasis on growthrelated changes. Zookeys. 859: 69-115. DOI: 10.3897/zookeys.859.32624.

Yokogawa K. \& Seki S. (1995). Morphological and genetic differences between Japanese and Chinese sea bass of the genus Lateolabrax. Japanese Journal of Ichthyology. 41(4): 437-445.

Yokogawa K., Taniguchi N. \& Seki S. (1997). Morphological and genetic characteristics of sea bass, Lateolabrax japonicus, from the Ariake Sea, Japan. Ichthyological research. 44(1): 51-60. 